\title{
A Review on Corrosion behaviour of Mn added Magnesium and its alloys
}

\author{
Mrs.Minal Sanjay Dani ${ }^{1}$, Dr. Vandana J Rao ${ }^{2}$, Dr. Indravadan B Dave ${ }^{3}$ \\ Assistant Professor, Metallurgy Department, Govt. Engg. College, Gandhinagar, India ${ }^{1}$ \\ Associate Professor, Met. \& Mat. Engg. Department, The M S University of Baroda, Vadodara, India ${ }^{2}$ \\ Principal, Mechanical Engg., Govt. Polytechnic Vyara, Surat, India ${ }^{3}$
}

\begin{abstract}
This research proposal provides corrosion behaviour of Manganese added Magnesium and its alloys. Magnesium is lightest of all Engineering metals and therefore it is attractive alternatives for Steels and aluminium. The corrosion of $\mathrm{Mg}$ and its alloys continues to be a major technological issue preventing wider usage of such alloys. Different corrosion like Galvanic corrosion, pitting corrosion, intergranular corrosion (IGC), filiform corrosion, crevice corrosion, stress corrosion cracking (SCC), and corrosion fatigue (CF) were already discussed for $\mathrm{Mg}$ alloys by different researchers ${ }^{[13]}$. In Magnesium- Aluminium $(\mathrm{Mg}-\mathrm{Al})$ alloys, the formation of intermetallic $\mathrm{Al}_{8}(\mathrm{Mn}, \mathrm{Fe})_{5}$ phase improves the corrosion resistance by removing elemental iron particles from the $\mathrm{Mg}$ and its alloy ${ }^{[10]}$. The corrosion rate examined via electrochemical and Weight loss method (Immersion test). It was seen that samples with Mn additions exhibited an increased Fe impurity tolerance level. This indicates that the Mn addition was able to moderate the effect of the $\mathrm{Fe}$ impurity on the corrosion of the $\mathrm{Mg}$ alloy. In addition, influencing factor of corrosion behaviour of $\mathrm{Mg}$ alloys like effect of allying element, Microstructure and secondary phases, grain size, effect of welding and heat treatment were discussed.
\end{abstract}

Keywords: Magnesium alloy; Manganese, Aluminium, Alloying Elements, Intermetallic phase; corrosion

\section{INTRODUCTION}

Magnesium is lightest of all engineering metals and Main target of research work is to modify Magnesium therefore is attractive alternatives for Steels and metal or Mg alloy with better corrosion resistance property Aluminium in areas of automobiles, electronic production and aerospace[7]. However, it is well recognized that the corrosion of $\mathrm{Mg}$ and its alloys continues to be a major technological issue preventing wider usage of such alloys. There is an overwhelming demand to develop magnesium alloys with an improved corrosion resistance, with a necessary precursor being a detailed and fundamental understanding of the role of key alloying elements and impurities.

Manganese is a common addition in Magnesium alloys. While Manganese containing $\mathrm{Mg}$ alloys can also show some improvements in corrosion resistance and ductility, Manganese additions have little effect on tensile properties. The addition of manganese is usually strategic and aimed at lowering the effect of the iron $(\mathrm{Fe})$ impurity content in order to control the overall corrosion of $\mathrm{Mg}-\mathrm{Al}$ alloys. In the presence of $\mathrm{Al}$ and $\mathrm{Fe}$, additions of $\mathrm{Mn}$ produce an $\mathrm{Al}_{8}(\mathrm{Mn}, \mathrm{Fe})_{5}$ phase that can moderate the corrosion rates caused by the impurity $\mathrm{Fe}$. This is important, when present in $\mathrm{Mg}$, any $\mathrm{Fe}$ is nominally insoluble and forms a pure-Fe (BCC) phase in the $\mathrm{Mg}$ matrix. This pure $\mathrm{Fe}$ has a large potential difference compared to the $\mathrm{Mg}$ and is able to support cathodic reactions efficiently and hence accelerates the corrosion rate dramatically ${ }^{[21]}$.

$\mathrm{Mn}$ also is sparingly soluble in $\mathrm{Mg}$, and in isolation it causes a major corrosion risk. The exact levels of Mn addition necessary to counter-act the detrimental effect of the Fe impurity are still unknown. which can be use as alternative of Aluminium alloys.

\section{LITERATURE REVIEW}

Manganese is a common addition in Magnesium alloys. While Manganese containing $\mathrm{Mg}$ alloys can also show some improvements. The purpose of this review is to provide an understanding of useful research directions for producing $\mathrm{Mg}$ and its alloys with lower corrosion rates ${ }^{[8]}$.

The need for fuel efficiency and increased performance in transportation systems continually places new demands on the materials used. The design criteria which automobile and aerospace industries are primarily concerned with are density, strength, stiffness, and corrosion resistance. Lowdensity materials may reduce fuel costs, increase range, and allow larger payloads. High strength and stiffness are necessary for adequate performance and safety characteristics, while corrosion resistance helps to ensure that design lifetime is achieved.

\section{A. Magnesium [2]:}

It is the 3rd most abundant metallic element in the earth's crust. Dolomite $\left(\mathrm{CaMgCO}_{3}\right)$, Magnesite $\left(\mathrm{MgCO}_{3}\right)$, Karnellite $\left(\mathrm{KMgCl}_{3} \cdot 6 \mathrm{H}_{2} \mathrm{O}\right)$ and Seawater $(0.13 \%$ of the element in the form of $\mathrm{MgCl}_{2}$.) are sources of $\mathrm{Mg}$. Production of $\mathrm{Mg}$ are done with Electrolytic method, Thermal-reduction method and Pidgeon method.

$\mathrm{Mg}$ has a good ductility, better noise and vibration dampening characteristics than Aluminum and excellent castability. 
IARJSET

International Advanced Research Journal in Science, Engineering and Technology

Vol. 2, Issue 12, December 2015

\section{TABLE I: COMPARISONS OF PHYSICAL PROPERTIES OF METALS}

\begin{tabular}{|l|c|c|c|}
\hline & Magnesium & Aluminum & Iron \\
\hline Crystal Structure & FCC & BCC & HCP \\
\hline Density & 1.74 & 2.70 & 7.86 \\
\hline $\begin{array}{l}\text { Coefficient of } \\
\text { thermal expansion }\end{array}$ & 25.2 & 23.6 & 11.7 \\
\hline Melting Point $\left({ }^{\circ} \mathrm{C}\right)$ & 650 & 660 & 1539 \\
\hline
\end{tabular}

Advantages of $\mathrm{Mg}$ [2]:

- Lowest density of all commercial casting alloys.

- Magnesium alloys have a comparable strength to weight ratio to Aluminum.

- Magnesium and its alloys also have a high vibration damping capacity.

- Electromagnetic interference reduction

- Full recyclability

Limitations of $\mathrm{Mg}$ [2]:

- Low strength and toughness

- Low corrosion resistance

- Easily flammable

B. Mg Alloys[1]:

- Resources of Mg Alloys Manufacturing :

- Sand Casting

- Die casting

- Squeeze casting

- Semi solid metal casting

- Spray forming/ Spray casting

- Melt infiltration methods

\section{Available Forms of Mg Alloys}

- Wrought products

Magnesium alloys are available as both castings and as wrought products. As castings, alloys can be cast in a variety of ways into near net shape products. In the wrought form, they can be obtained as extruded bars and shapes, forgings and rolled plates and sheets. Automobile application over $\mathrm{Al}$ alloys.

- Most common Cast alloys are

AZ63, AZ81, AZ91, AM50, AM60, ZK51, ZK61, ZE41, ZC63, HK31, HZ32, QE22, QH21, WE54, WE43, Elektron 2

Fig. 1. Some automotive components made of $\mathrm{Mg}$ alloy and obtained weight reduction[14]

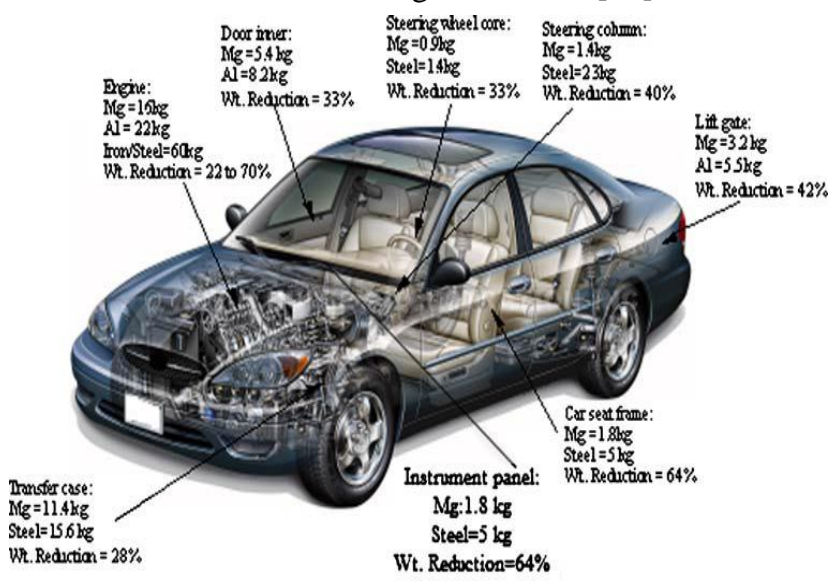

\begin{tabular}{|c|c|c|c|c|c|c|}
\hline Property & Unit & AZ91 & AM60 & AM50 & AM20 & AE42 \\
\hline Ultimate Tensile & $\mathrm{MPa}$ & 240 & 230 & 210 & 240 & 220 \\
\hline Tensile YS & $\overline{\mathrm{MPa}}$ & 160 & 130 & 125 & 90 & 140 \\
\hline Compressive YS & $\mathrm{MPa}$ & 148 & - & 113 & 74 & 106 \\
\hline Fracture Elong. & $\%$ & 7 & 13 & 15 & 20 & 15 \\
\hline Elastic Modulus, & $\mathrm{GPa}$ & 45 & 45 & 45 & 45 & 45 \\
\hline Brinell hardness & HBS & 70 & 65 & 60 & 45 & 60 \\
\hline Impact strength & J & 9 & 18 & 18 & 18 & 16 \\
\hline
\end{tabular}

TABLE II TYPICAL MECHANICAL PROPERTIES OF MG ALLOYS AT ROOM TEMPERATURE

Some Developments of Mg alloys[1]:

Magnesium forged alloy wheels:

Fig:2This is ZK30 with $\mathrm{Zn}$ and $\mathrm{Zr}$ is lighter than Aluminum forged wheel which is used in Audi A8 series.

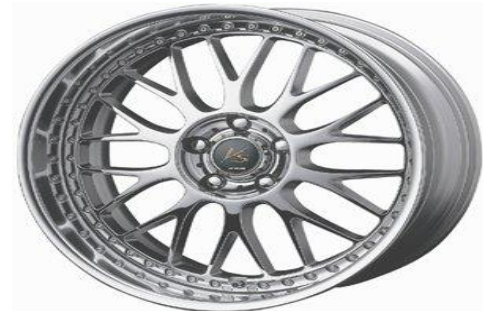

Machining Rolling slab:

Fig:3Made from Electron 43, High strength $\mathrm{Mg}$ alloys which used in Aircraft seat. Mg alloy with Yitrium,rare earth and $\mathrm{Zr}$.

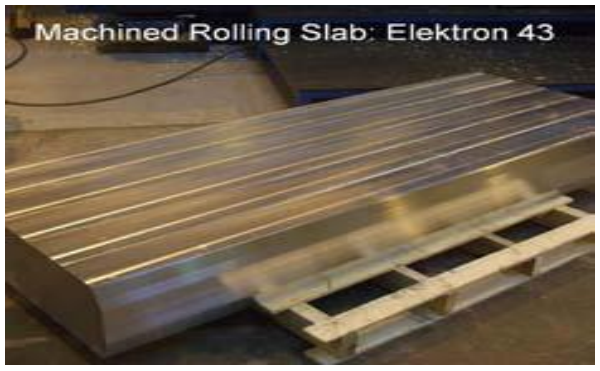

Handrails for city bus made byAZ31B:

Fig:4The curved, extruded magnesium tubing forms handrails that are lighter, thinner and stronger than Aluminum handrails.

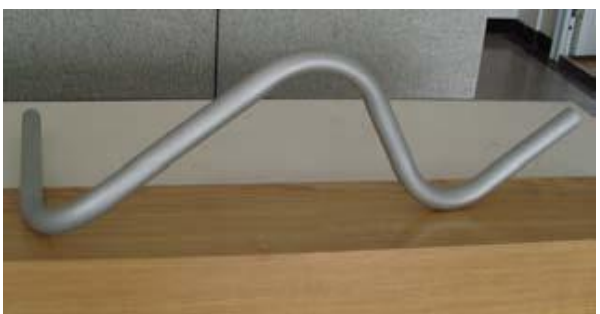

Magnesium Engine Front Covers Lighten the Load:

Fig:5Compared to Aluminum, the area tension pulley is strengthened in the magnesium cover, due to a high bending moment and compaction behavior. As engines 
become ever-lighter with magnesium, improved fuel economy and durability compare with Aluminum alloys.

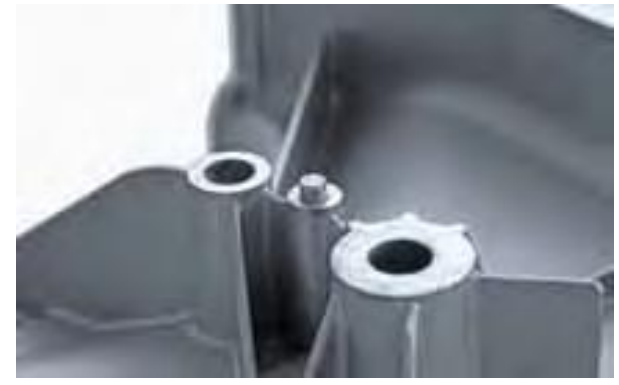

\section{Effect of alloying elements on Magnesium:}

Many alloying elements can be useful in a variety of different applications whereas others are only ideal for very specific applications due to the change in properties.

\section{Aluminum}

- The maximum solubility is 11.5 at \% (12.7 mass \%) and alloys in excess of 6 mass \% can be heat treated.

- Aluminum improves strength, the optimum combination of strength and ductility being observed at about $6 \%$.

- Alloys are readily castable.

- The creep resistance is limited due to the poor thermal stability of the Mg17Al12 phase.

\section{Calcium:}

- Alloying with calcium is becoming more common in the development of cheap creep resistant alloys essentially replacing $\mathrm{Mg} 17 \mathrm{Al} 12$ with $\mathrm{Al12Ca}$

- Ca can act as a deoxidant in the melt or in subsequent heat treatment.

- It improves the roll ability of sheet but $>0.3$ mass $\%$ can reduce the weld ability.

\section{Cerium:}

- Improves corrosion resistance.

- Increases plastic deformation capability, magnesium elongation, and work hardening rates.

\section{Manganese:}

- Increases saltwater corrosion resistance within some Aluminum containing alloys.

- reduces the adverse effects of iron, usually present in .2.4 weight percent.

- Binary alloys (M1A) are used in forgings or extruded bars. The maximum amount of manganese is 1.5-2 mass $\%$.

\section{Silicon:}

- It can increase molten alloys' fluidity

- Improves elevated temperature properties, especially creep resistance

- Only used in pressure die casting.

\section{Rare Earth Metals:}

- Increase in high temperature creep and corrosion resistance and strength

- Allows lower casting porosity and weld cracking in processing.

Fig 6 : Effect of alloying elements on corrosion rate of $\mathrm{Mg}$ alloy

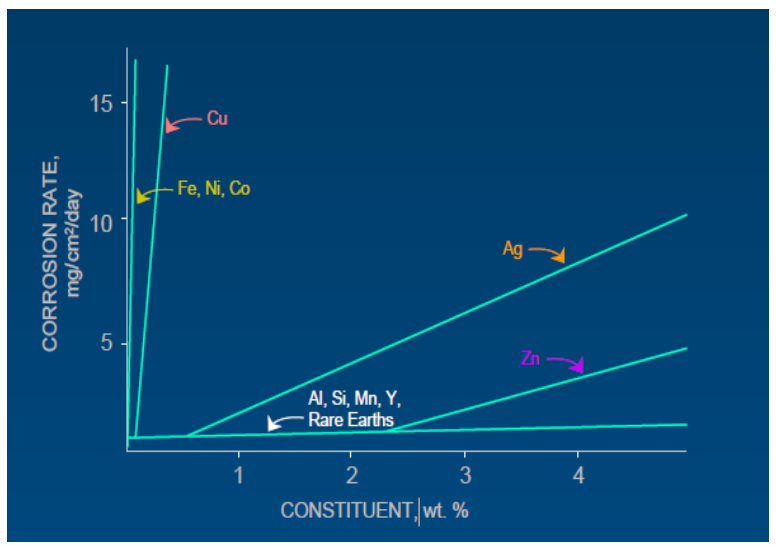

\section{Mn Addition in Mg Alloys[2]:}

Manganese is added mainly for corrosion resistance. In $\mathrm{Mg}-\mathrm{Al}$ alloys, Manganese combines with the detrimental impurity iron and precipitates it to the bottom of the melt as $\mathrm{Al} 5(\mathrm{Mn}, \mathrm{Fe}) 2[10]$. In addition to reducing the soluble iron content in the alloy melt, the manganese, addition also passivates the residual iron that remains in solution provided the content is less than a critical limit for the alloy, referred to as the critical $\mathrm{Fe} / \mathrm{Mn}$ ratio. Manganese additions can be problematic since the melting point of manganese is high and the solubility of manganese is reduced with Aluminum in the melt. Various manganese additives and addition techniques can be used. Mn can be added as anhydrous $\mathrm{MnCl} 2$ flake, or as electrolytic manganese in the form of flake or briquettes[2]. While manganese containing $\mathrm{Mg}$ alloys can also show some improvements in corrosion resistance and ductility, Mn additions have little effect on tensile properties.

Fig:7Effect of addition of $\mathrm{Mn}$ in $\mathrm{Mg}-\mathrm{Al}$ alloy

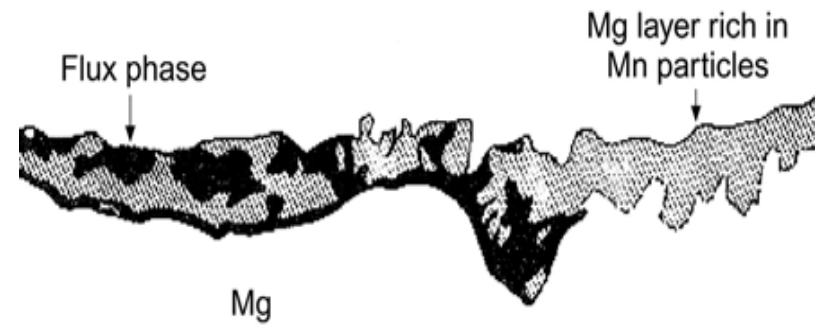

\section{Corrosion behavior of $\mathrm{Mg}$ metal and Mg alloys}

Magnesium alloys are corroding metals because of their active positions in both the electromotive force (EMF) series and the galvanic series for seawater. Depending on the environment and certain design considerations, the corrosion of magnesium can be well within acceptable design limits. (it is between steel and Aluminum). Knowledge of environmental factors that influence degradation, types of corrosion to which magnesium alloys are most susceptible, protection schemes, and design considerations can significantly minimize corrosion and increase use of this family of lightweight structural metals[2]

Pure magnesium is exposed to the air at RT, a gray oxide forms on its surface. Moisture converts this oxide to magnesium hydroxide, which is stable in the basic range of $\mathrm{pH}$ values, but is not in the neutral or acid ranges. As a 
result, in neutral and low $\mathrm{pH}$ environments magnesium dissolution is accompanied by hydrogen evolution. In basic environments, passivation is possible as a result of the formation of a $\mathrm{Mg}(\mathrm{OH})_{2}$ layer on the metal surface[5].

\section{Metal - metal ion equilibrium and Electrodepotential}

$$
\begin{array}{lr}
\mathrm{Au}-\mathrm{Au}+3 & 1.498 \\
\mathrm{Ag}-\mathrm{Ag}+ & 0.799 \\
\mathrm{H} 2-\mathrm{H}+ & 0.0 \\
\mathrm{~Pb}-\mathrm{Pb}+2 & -0.126 \\
\mathrm{Sn}-\mathrm{Sn}+2 & -0.136 \\
\mathrm{Ni}-\mathrm{Ni}+2 & -0.250 \\
\mathrm{Co}-\mathrm{Co}+2 & -0.277 \\
\mathrm{Cd}-\mathrm{Cd}+2 & -0.403 \\
\mathrm{Fe}-\mathrm{Fe}+2 & -0.440 \\
\mathrm{Cr}-\mathrm{Cr}+3 & -0.744 \\
\mathrm{Zn}-\mathrm{Zn}+2 & -0.763 \\
\mathrm{Al}-\mathrm{Al}+3 & -1.662 \\
\mathrm{Mg}-\mathrm{Mg}+2 & -2.363 \\
\mathrm{Na}-\mathrm{Na}+ & -2.714
\end{array}
$$

TABLE:III METAL ION ELECTRODE POTENTIAL

\section{Types of Corrosion observed in Mg and its alloy}

\section{Galvanic corrosion[10]}

Magnesium alloys are highly at risk to galvanic corrosion as anodic behavior to the metals. Galvanic corrosion forming by placing two dissimilar metals in corrosive conductive solution. In this process electron flow produce from corroded (Anodic) to protected metal (Cathodic)(fig:9). Magnesium and its alloys are highly susceptible to galvanic corrosion due to it has lowest standard potential in EMF series. From the table3, we can say that $\mathrm{Mg}$ can corrode by the contact of other metal andby $\mathrm{H}_{2}$ evolution.

When magnesium and magnesium alloys contain second phases because of impurities or alloying elements, the matrix $\alpha$-phase is corroded, while the hydrogen gas is evolved on the second phases. Table 3 shows typical corrosion potential values for magnesium and common magnesium alloy second phases.

\begin{tabular}{|c|c|c|c|}
\hline Metal $\mathbf{E}_{\text {corr }}$ & VSCE & Metal $\mathbf{E}_{\text {corr }}$ & VSCE \\
\hline $\mathrm{Mg}$ & -1.65 & $\mathrm{~A} 18 \mathrm{Mn} 5(\mathrm{Fe})$ & -1.20 \\
\hline $\mathrm{Mg} 2 \mathrm{Si}$ & -1.65 & Beta-Mn & -1.17 \\
\hline Al6Mn & -1.52 & $\operatorname{Al} 6 \mathrm{Mn}(\mathrm{Fe})$ & -1.10 \\
\hline Al4Mn & -1.45 & $\mathrm{Al} 3 \mathrm{Fe}(\mathrm{Mn})$ & -0.95 \\
\hline $\mathrm{Al} 8 \mathrm{Mn} 5$ & -1.25 & $\mathrm{Al} 3 \mathrm{Fe}$ & -0.74 \\
\hline
\end{tabular}

\section{Fig:8,9 Galvanic Corrosion}
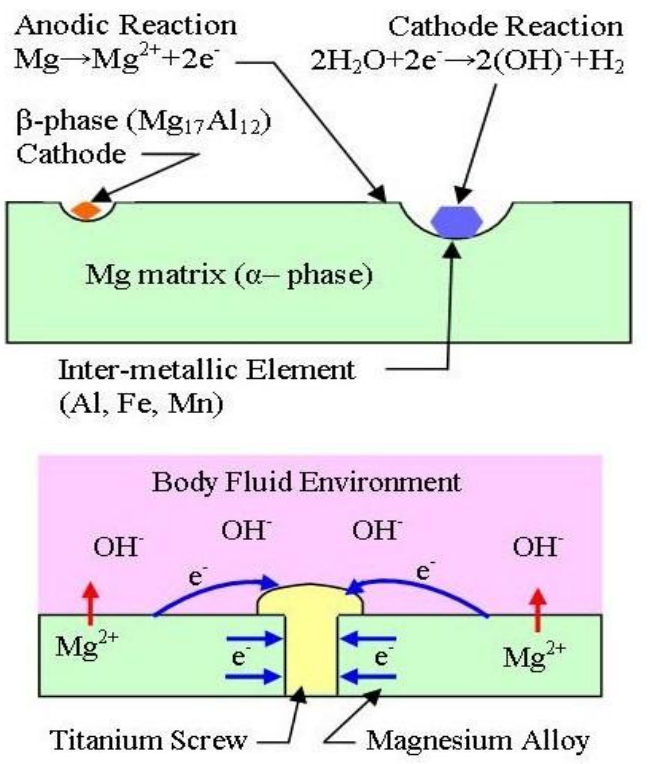

\section{Pitting corrosion[10]}

In $\mathrm{Mg}$ alloys, Pitting corrosion occur at free corrosion potential of magnesium, when exposed to chloride ions in a non-oxidizing medium. The as-extruded magnesium alloy AM60 was immersed in natural 3.5\% $\mathrm{NaCl}$ solution, and the corrosion pits occurred on the surrounding of AlMn particles. The alloy has a protective oxide film in air. The potential of $\mathrm{MgO}(+1 \mathrm{~V})$,. when it is immersed in a sodium chloride aqueous solution, $\mathrm{C} 1$ - ions will absorb on the $\alpha-M n$ areas bordering on Al-Mn particles.

Fog:10Pitting morphology of extruded AM60 in $3.5 \% \mathrm{NaC} 1$ aqueous solution

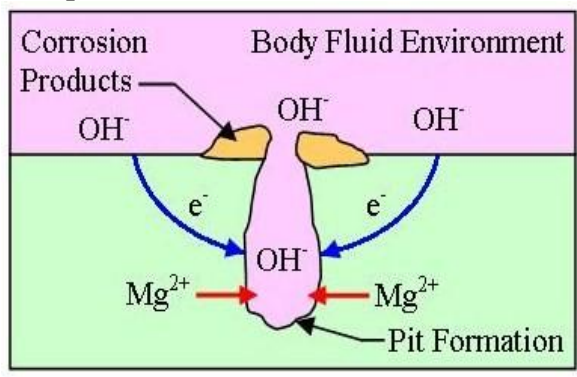

Anodic reaction: $\quad \mathrm{Mg}=\mathrm{Mg}^{2+}+2 \mathrm{e}$

Cathodic reaction:

$$
2 \mathrm{H}_{2} \mathrm{O}+2 \mathrm{e}=2 \mathrm{H}_{2}+20 \mathrm{H}^{-}
$$

Total reaction: $\quad \mathrm{Mg}+2 \mathrm{H}_{2} \mathrm{O}=\mathrm{Mg}(\mathrm{OH})_{2}+2 \mathrm{H}_{2}$

$\mathrm{Mg}$ hydroxide precipitates on the bottoms of pits and surfaces of samples.

TABLE:IV CORROSION POTENTIAL VALUES FOR MAGNESIUM AND FOR COMMON MAGNESIUM SECOND PHASES (AFTER $2 \mathrm{H}$ IN DEAERATED 5\% NACL SOLUTION SATURATED WITH $\mathrm{MG}(\mathrm{OH})_{2}(\mathrm{PH} 10.5)$.

\section{- Intergranular corrosion[10]}

Intergranular corrosion (IGC) occurs at the grainboundaries due to the precipitation of secondary phase. However, recent studies show that IGC can occur on $\mathrm{Mg}$ alloys. VALENTE noticed of IGC occurred in WE43 in $3.5 \% \mathrm{NaCl}$ aqueous solution. In early stages of immersion, a localized attack of $\mathrm{Mg}$ and its alloy can form grain boundaries at interface of cathodic precipitation in mild corrosive media which considered as IGC.

Fog:11Intergranular corrosion morphology of AZ80-T5 in $3.5 \% \mathrm{NaCI}$ aqueous solution after $1 \mathrm{~h}$.

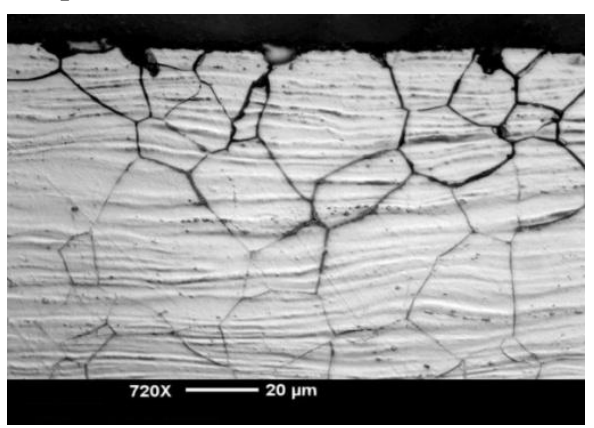




\section{Filiform corrosion}

Filiform corrosion is caused by an active corrosion cell which moves across a metal surface. The head is the anode and the tail the cathode. Filiform corrosion occurs under protective coatings and anodized layers. Uncoated pure magnesium does not undergo filiform corrosion[13].

\section{Crevice corrosion}

It is reported that crevice corrosion does not occur with the magnesium Alloys[13].

\section{Stress corrosion cracking $(\mathrm{SCC})$ :[10]}

Stress corrosion cracking means cracking due to the effect of tensile stress and corrosive. Pure megnesium has good resistance to SSC in both atmospheric and aquaousenvirnonment. But; Aluminium is susceptible to sscsi so it making alloys asAZ61,AZ80, and AZ91 with 6,8 , and $9 \%$ aluminium respectively. Magnesium is mainly transgranular. Sometimes intergranular SCC occurs as a result of $\mathrm{Mg}_{17} \mathrm{Al}_{12}$ precipitation along grain boundaries in $\mathrm{Mg}-\mathrm{Al}-\mathrm{Zn}$ alloys[11].

\section{- Corrosion fatigue [10]}

Corrosion fatigue directly relates humidity. Fatigue strength and Humidity have inversely proportional relation.It has also been found that corrosion fatigue cracks propagate in a mixed transgranular-intergranular mode and that the corrosion fatigue crack growth rate was accelerated by the same environments that accelerate stress corrosion crack growth. AZ91-T6 has resistance to corrosion fatigue reduced in $3.5 \%$ salt water relative to that in air.

\section{Influencing factors of corrosion behavior of Mg Alloys - Metallurgical influence:[8]}

1.Alloying elements: Alloying elements like $\mathrm{Fe}, \mathrm{Co}, \mathrm{Ni}$ and $\mathrm{Cu}$ are detrimental for the corrosion of magnesium alloys. Corrosion resistance improves with the A1 content. The corrosion rate of AZ91, AZ61 and AZ31 in $5 \% \mathrm{NaCl}$ solution increasedwith the decrease of $\mathrm{A} 1$ content.Mn can improve the corrosion resistance of magnesium alloys. Binary Al-Mn phase with lower AlMn ratio has higher cathode potential. Therefore, the corrosion rate increases when $\mathrm{Mn}$ is added into $\mathrm{Mg}$ - $\mathrm{A} 1$ magnesium alloys to form $\mathrm{A} 1-\mathrm{Mn}$ and intermetallic phase $\mathrm{Al}-\mathrm{Mn}-\mathrm{Fe}$ [22].For example, salt fog corrosion tests for Mn-containing $\mathrm{Mg}$ A1 magnesium alloys such as AM50 and AM20, showed corrosion that pits initiated at low A1 areas, the matrix was attacked in the form of fissures. The fissures started from pitting locations and usually stopped in front of areas of high A1 segregation [22]. The continuous high Al segregation seemed to contribute much more in stopping the propagaijon of corrosion fissures than the discontinuous, more or less isolated, $\mathrm{p}-\mathrm{MgI7All2} \mathrm{p}$ articles [22]. Mn can improve the corrosion resistance of magnesium alloys, but this is not always the case. The corrosion rate of magnesium alloys is related to iron content and $\mathrm{Fe} / \mathrm{Mn}$ ratio. Binary $\mathrm{Al}-\mathrm{Mn}$ phase with lower AVMn ratio has higher cathode potential. Therefore, the corrosion rate increases when $\mathrm{Mn}$ is added into $\mathrm{Mg}$ - $\mathrm{A} 1$ magnesium alloys to form A1-Mn and intermetallic phase Al-Mn-Fe [22].
$\mathrm{Zr}$ can stabilize the magnesium matrix phase and reduce its corrosion rate. The beneficial effect of $\mathrm{Zr}$ cannot be extended to an alloy with too much $\mathrm{Zr}$. The excess addition of $\mathrm{Zr}$ can lead to precipitation of $\mathrm{Zr}$ in the matrix, which is detrimental to the corrosion [23].

In addition, rare earth improves also the corrosion resistance of magnesium alloys, but is affected by medium and $\mathrm{pH}$ value[21].

\section{Microstructure and secondary phases[10]:}

Table $\mathrm{V}$ shows that the corrosion potential of AlMn is higher than that of Mgl7AIl2T.Thus, AlMn is more detrimental than $\mathrm{Mg}_{17} \mathrm{Al}_{12}$.

\begin{tabular}{|l|l|l|}
\hline Sr.No. & Phase & o corr/V \\
\hline 1 & $\mathrm{Mg}$ & -1.55 \\
\hline 2 & AlMn & -1.28 \\
\hline 3 & $\boldsymbol{B}(\mathrm{Mg} 17 \mathrm{~A} 112)$ & -1.31 \\
\hline
\end{tabular}

TABLE :V CORROSION POTENTIAL OF PURE PHASES AFTER 3 H IMMERSION IN ASTM D1384 WATER (INITIAL PH= 8.3)

\section{GRAIN SIZE[10]:}

The rapid solidification process can refine the microstructure which is beneficial to the corrosion properties. It can change the mechanism of corrosion turning pitting corrosion of $\mathrm{Mg}-\mathrm{Al}$ magnesium alloys into overall corrosion. The surface or skin layer of die-cast Mg-A1 magnesium alloys with very fine grains, high $\beta$ volume fraction and continuous distribution of $\beta$ phase along grain boundaries has a higher corrosion resistance than its core . It is the same that die castings of magnesium alloy AZ91D have better corrosion resistance than ingots.

\section{Effects of post processing : Heat treatment[10]}

Heat treatment can change the microstructure of magnesium alloys. Aging makes A1 atoms diffuse towards grain boundaries and form precipitation of the $\beta$ phase, thus, reducing the Aluminum concentration in the $\alpha-\mathrm{Mg}$ matrix.

\section{Effects of welding [10]:}

HAFERKAMP et a1made some investigations on the corrosion behavior of laser welded AZ91D in synthetic seawater. Fig 12 shows the corrosion morphology of the weld zone of AZ91D weld with gas tungsten arc (GTA) welding after $48 \mathrm{~h}$ salt fog test. The corrosion morphology of the weld zone of AZ31 with laser beam welding after $24 \mathrm{~h}$ salt frog test is shown in Fig.12. It is visible that the corrosion does not attack the weld zone.

Fig 12:Corrosion morphology of weld zone of AZ31 with laser beam welding

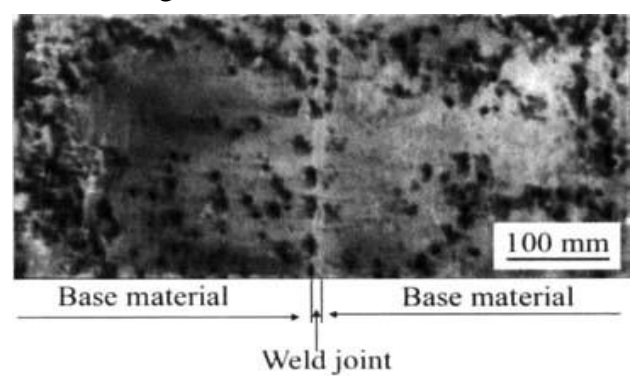




\section{Environmental influence:}

Corrosion of magnesium alloys increases with the increase of relative humidity $(\mathrm{RH})[23]$. High humidity accelerates SCC during atmospheric exposure [13]. The fatigue life is reduced, and the FCP rate is enhanced by the increasing environmental temperature and relative humidity $(\mathrm{RH})$.

\section{Electrolyte pH value:}

The $\mathrm{pH}$ value of the medium has an important impact on the corrosion morphology and the number of pits. As a result, the corrosion of magnesium alloys in neutral or alkaline salt solutions typically takes the form of pitting [23].

Fig 13: Corrosion morphologies of AM60 as extruded in $3.5 \% \mathrm{NaC} 1$ aqueous solution at $\mathrm{pH}=3(\mathrm{a}), \mathrm{pH}=7$ (b) and $\mathrm{pH}=12(\mathrm{c})$, respectively

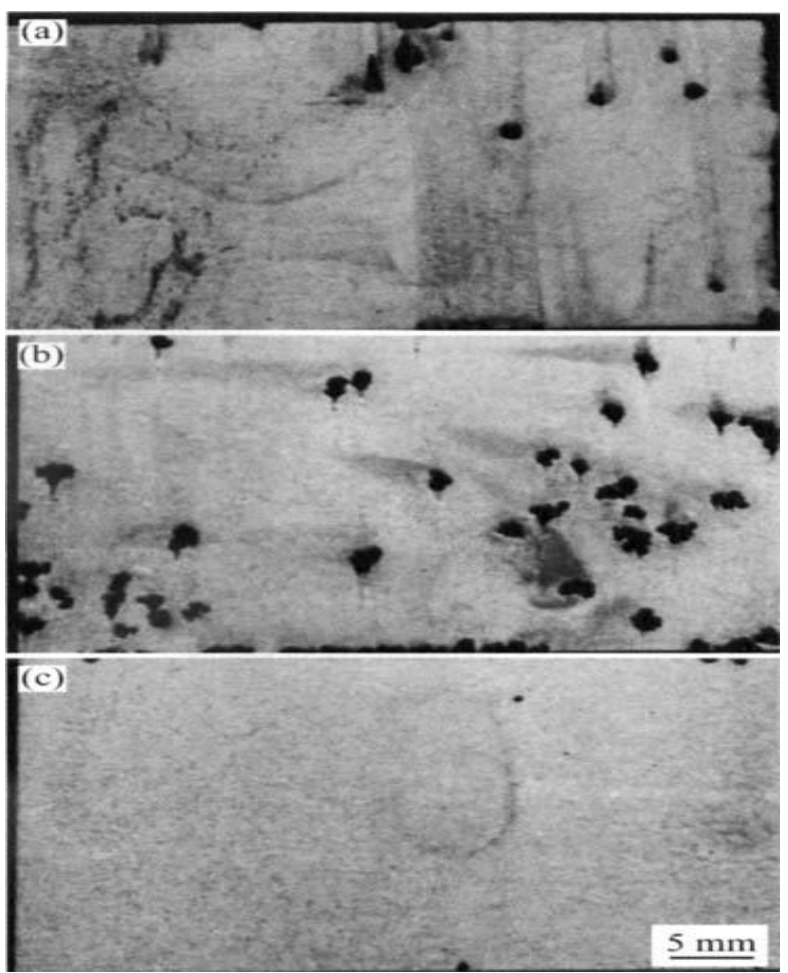

2.Chloride ion concentration[23]:

Extruded Magnesium alloys with 3\% to $8 \%$ A1 and $0.5 \%$ $0.8 \% \mathrm{Zn}$ are susceptible to filiform corrosion and pitting corrosion in aqueous chloride solutions depending on chloride concentration

\section{Corrosion rate measurement techniques for $\mathrm{Mg}$ metal and Alloys [17]:}

Different corrosion tests are carried out on $\mathrm{Mg}$ metal and $\mathrm{Mg}$ alloys as follows:

\section{Weight loss method (Immersion test)}

Here samples were cut in regular size of 15 X 15 dia mm and polished with $80,220,400,600$ grit emery papers. They were polished with $0.25 \mu \mathrm{m}$ diamond paste and cleaned with acetone. Exact weight of samples were taken and they were immersed into the solution of $3.5 \% \mathrm{Nacl}$ in beaker for $100 \mathrm{hrs}$. After immersion test the samples were cleaned with $200 \mathrm{gms} / \mathrm{l} \mathrm{CrO} 3+19 \mathrm{gm} / \mathrm{l} \mathrm{AgNo} 3$ solution for $10 \mathrm{~min}$ to remove the corrosion products. It was again wash with distilled water and weighted. The difference between initial and final weight gives the corrosion weight loss.Thus Immersion test will give Corrosion rate for 100 $\mathrm{hr}$ in $3.5 \mathrm{NaCl}$ solutions for mg metal and different $\mathrm{Mg}$ alloys.

\section{Electro chemical tests :}

It is carried out using Potentiodynamic anodic polarization method in ASTM D 1384 solution. The ASTM D 1384 solution contain $148 \mathrm{mg} / \mathrm{l}$ of $\mathrm{Na} 2 \mathrm{SO} 4,138 \mathrm{mg} / \mathrm{l}$ of $\mathrm{NaHCO} 3$ and $165 \mathrm{mg} / \mathrm{l} \mathrm{Nacl}(\mathrm{Ph}=8.3)$. All corrosion test were carried out at RT using I lit five neck ASTM electrochemical cellconsisting of three working electrodes, reference electrod( $\mathrm{Ag} / \mathrm{AgCl}-\mathrm{sat})$, counter electrode $(\mathrm{pt})$, and working electrodes(W). Solartron 1287 electrochemical interface was used for the polarization experiments. During electrochemical corrosion test, the electrode potential was anodically scanned at a scan rate of $10 \mathrm{mV} / \mathrm{min}$ from $-1400 \mathrm{mV}$ towards anodic potential. All the electrode potential was measured against $\mathrm{Ag} / \mathrm{AgCl}$ (in saturated $\mathrm{KCl}$ ) reference electrode.

\section{Outlook:}

Magnesium and its alloys producers usually add more manganese to reduce the iron content in the melting. Mn, reacting with $\mathrm{Al}$, forms $\mathrm{Al} 5(\mathrm{Mn}, \mathrm{Fe}) 2$ phase, which has a highest noble potential and at the same time it decreases the formation of $\alpha$ phase. A review of the current research on Magnesium and its alloys corrosion and its corresponding mechanisms in the industry such as galvanic corrosion, pitting, stress corrosion, intergrannular corrosion and corrosion fatigue has been expressed. The corrosion mechanisms of magnesium alloys are still not well understood. Therefore, it is definitely necessary to continue this investigation. There is a challenge for corrosion scientists to create a $\mathrm{Mg}$ alloy with better corrosion resistance.

Because of the well-known characteristics of magnesium and its alloys with high susceptible to corrosion, new $\mathrm{Mg}$ alloys including cast and wrought alloys with better properties such as finer grain, new phases should be developed, more feasible, reliable, maintainable and cheaper protection systems and higher techniques must be investigated to match with the practical applications. Moreover, according to the eco-friendly requirements, more considerations on recycling should be given both in industrial environment and bioenvironment.

\section{REFERENCES}

[1] http://www.intlmag.org

[2] Magnesium Alloys and Technologies. by Karl U. Kaine

[3] www.okokchina.com

[4] ASM handbook, Volume 13, Corrosion,ASM International, $4^{\text {th }}$ Ed. 1992

[5] Mg and Mg alloys in Uling's Corrosion Handbook, 2000.pg.793830

[6] http://www.hindustanmagnesium.com for aerospace industry

[7] www.asminternational.org Corrosion Resistance of Magnesium Alloys

[8] Revised by Barbara A. Shaw, Pennsylvania State University, ASM Handbook, Volume 13A Corrosion: Fundamentals, Testing, and Protection (\#06494G)

[9] M.R. Bothwell, in The Corrosion of Light Metals, John Wiley \& Sons, 1967, p 269

[10] ZENG Rong-chang', HANG Jin HUANG Wei-', W. DIETZEL',K. U. KAINER2, C. BLAWERT2, KE Wei3, Trans. Nonferrous Met. 
SOC. China 16(2006)s763-s771, Available online at www.sciencedirect.co19

[11] C. Suman, Paper 900794, Society of Automotive Engineers, 1990

[12] S. Jayalakshmi, Q.B. Nguyen, M. Gupta, Materials Chemistry and Physics, Volume 134, Issues 2-3, 15 June 2012, Pages 721727

[13] Dr.Sung,Advance Engineering Materials,2005,7,no.7(Recent progress in corrosion and it's protection for $\mathrm{Mg}$ alloys)

[14] T. Tański*, K. Labisz, L.A. Dobrzański,'effect of Al addition and heat treatment"AMME,vol 44 issuew 1, 2011

[15] A.V. Sameljuk *, O.D. Neikov, A.V. Krajnikov, Yu.V. Milman,G.E. Thompson , Corrosion Science 46 (2004) 147-158, www.elsevier.com/locate/corsci

[16] Gonzalo Galicia a, Nadine Pébère b, Bernard Tribollet a, Vincent Vivier a, ${ }^{*}$ LISE - UPR 15 du CNRS, Université Pierre et Marie Curie, 4 place Jussieu, 75252 Paris Cedex 05, France b Université de Toulouse, CIRIMAT, UPS/INPT/CNRS, ENSIACET, 118 route de Narbonne, 31077 Toulouse Cedex 04, France

[17] Andrej Atrens a, Guang-Ling Song a,1, Fuyong Cao a, Zhiming Shi a, Patrick K. Bowen, a The University of Queensland, Materials Engineering, Brisbane, Qld 4072 Australia ,Michigan Technological University, Received 20 August 2013,ScienceDirect,Journal of Magnesium and Alloys 1 (2013) 177e200,www.elsevier.com/journals/journal-of-magnesium-andalloys/2213-9567

[18] Dictionary of Metals,Edited by Harold M. Cobb,ASM international.

[19] D.S. Gandel, N. Birbilis, M.A. Easton, M.A. Gibson, 'Influence of Manganese, Zirconium and Iron on the Corrosion of Magnesium' Corrosion \& prevention, 2010, Paper 118, p. 1.

[20] Kelvii Wei Guo*, "A Review of Magnesium/Magnesium Alloys Corrosion and its Protection" Recent Patents on Corrosion Science, 2010, 2, 13-21

[21] STEPHENS R I, SCHRADER C D, LEASE K B. Corrosion fatigue Of AZ91E-T6 cast magnesium alloy in a 3.5 percent $\mathrm{NaCl}$ aqueous environment.[J]Journal of engineering technology

[22 ] ELIEZER D, UZAN P, AGHION E. Effect of second phases on the corrosion behavior of magnesium alloys $[\mathrm{J}]$. Material Science 2003,419-422: 857-866

[23] SONG G Recent progress in corrosion and protection of magnesium alloys [J]. Advance Engineering Materials, 2005,7(7): 563-586. 